\title{
Decentering of Anthropocentric Interactions and Restructuring of Ecocentric Dialogues in the Interdependence between Man and Nature through Fantasy and Fictional Narratives
}

Silpa Krishnan V S

MA English

Pondicherry University

Kalapet, Puducherry (UT), India

silpakvs@gmail.com

Priyanka Tresa Paul

MA English

Pondicherry University

Kalapet, Puducherry (UT), India

priyankatresapaul@gmail.com

\section{Abstract}

Since the onset of industrialization around the year 1800, along with its growing dependence on fossil fuels, have moved us from the Holocene era and into what is now being called the Anthropocene era. Much of the meaning attributed to the human- nature interaction is anthropocentric and this has resulted in causing a disturbing dialogue between nature and man. Many authors have tried to reform anthropocentric signs into the nature-centric sign to convey environmentalist themes and signify the natural environment as independent, culturally complex, and worthy of humanity's respect. The paper aims to elaborate on the 
applicability of eco semiotics in literary analysis, especially in regards to fantasy and fictional literature. With the help of Antoine de Saint-Exupéry's The Little Prince, Rudyard Kipling's The Jungle Book, the 2016 animation film Moana, and the 2009 sci-fi film Avatar, this paper will examine the literature concerning eco semiotics(natural symbols and their interpretation across cultural-ecological boundaries) in an effort to provide an alternative to the positivist approach inherent in much contemporary environmental thought that has contributed to the present environmental crisis (Verhagen, 2008).

Keywords: Ecosemiotics, Ecocriticism, Ecosystem, Fiction, Fantasy

Introduction

The overutilization of nature and its resources for the benefit of mankind has submitted the planet to rapid environmental degradation. As mankind evolved, the need for more space and more material means elevated the rate at which we depend on our natural resources. Though we have found alternative resources and eco-friendly initiatives that would reduce our dependence on nature, it hardly meets the mark for a significant shift. This dependence of man on the environment has surpassed the safer stratum and is now being desperately pushed into a state of complete exhaustion of resources. Rockstrom et al. (2009) have identified that we have gone beyond three of the nine boundaries within which humans can operate and exist safely (climate change, rate of biodiversity loss and global nitrogen cycling). From being in an environmental crisis, we have become the sole reason for perpetuating an environmental crisis (Evernden, 1993).

The changing environmental structure invites us to re-examine and redefine the way in which we perceive nature and its subjects. A semiotic approach that is more qualitative and meaning-based will help us to understand the diverse relations and the intrinsic value of all aspects of the system. Kull (2005) states that through a shift in our understanding of the 
environment- both qualitative and relational perspectives-we can change the many practices in our complex ecological and cultural system. Culture as constructive and representative as it is considered the politics of producing, preserving, and propagating the codes of meaning or identity markers existing in the system. Culture forms a dialogue to interact and navigate through the complex semiotic interrelations regulating between the verbal and non-verbal living entities of the environment. Bruni (2001) states the ecological crisis as a cultural crisis and semiotic approach helps to address and form a discourse on the cultural and political aspects of environmental degradation.

Our perspective will have a deep impact on the manner in which we interact with nature and the way we situate ourselves within our surroundings. Such views tend to construct a pattern of consumption of resources suitable to the needs of the growing society. Much of the meaning attributed to the human- nature interaction is anthropocentric and this has resulted in causing a disturbing dialogue between nature and man. The crisis that we have found ourselves in can only be averted by creating a common platform for sharing and understanding mutual reflection. Many authors have tried to reform anthropocentric signs into the nature-centric sign to convey environmentalist themes and signify the natural environment as independent, culturally complex, and worthy of humanity's respect. Thus it is evident that the solutions for the rapid changes in climatic conditions and environmental degradation require not only a shift in the way we utilize nature but also in the way we perceive it. A paradigm shift is our best chance at longer and sustainable development of ecosensitive culture. A change in the way we approach nature, placing nature and its flora and fauna at par with each other, creating a balanced equilibrium of exchange and of shared respect will have a significant positive impact on environmental outcomes. A restructuring of the interactions between man and nature in literature and literary productions could pave way 
for a culture rooted in the preservation and protection of nature and also for producing the need for eco-sensitivity in all our activities.

Ecocriticism as a field of study incorporating literature and environment deals with the interrelation between the two and "analyze texts that illustrate environmental concerns and examine the various ways literature treats the subject of nature. It takes an interdisciplinary point of view by analyzing the works of authors, researchers, and poets in the context of environmental issues and nature"(Ecocriticism). Ecocriticism portrays the allegorical, metaphorical or literal relation between man and its natural environment and ecocriticism analyses these relationships on how they are influential on a broader perspective.

Ecosemiotics studies the sign systems and how " sign processes in culture, which relate to other living beings, communities, and landscapes"(Ecosemiotics). It is concerned with the signs, sign systems, and sign-functions with regard to nature. Semioticians have divided eco semiotics into three, namely, anthroposemiotics which includes humans and verbal communications, zoosemiotics concerns to animals and mostly non-verbal communications and phytosemiotics relates to plants and entirely nonverbal communications. Excessive anthropocentrism in literary productions overshadowed the voices of other patterns of interaction between the natural environment and humans. These anthropocentric signs are inherent in our language for so long that they have become associated as a part of the system. The language system then gave these signs and signifiers authenticity to be included and normalised as a part of cultural entities.

A majority of the literary productions available today places more reliance on humancentered narratives. Human-centered narratives aka anthropocentric narrative works had created an unconscious shift in the dialogue between man and nature, thus placing man at the center and nature as an affinity that grows around him, for his expression and existence, for his well-being and to satisfy his needs. This symbolic association of man at the center shifts 
the rest of the subjects towards the margins. This leads to an essentializing of all thingsnatural and artificial- for the one purpose of providing or creating the most suitable living condition for humans. Such literary works divorce the reader from a natural setting even as it tries to describe it by increasing the communication gap between the two. As long as one is used to essentialize the other there will be an imbalance in the dialogue. The signs that exist in such literary works help to cultivate a human-centered meaning system.

Eco-semioticians should find a way to bridge the gap in the discourses between man and nature. Without the restoration of balance between these discourses, the problems faced by nature cannot be addressed efficiently. Nature cannot be described using the signs that are produced to describe and convey human expressions. Nature's ability of speech should be restored in order to initiate a shift towards a more equal and respectable interaction with human beings. Timo Maran argues for integrating eco semiotics with literary analysis, "to pinpoint the problems in our communicative relations with [nature], and may be even explicate possibilities for the restoration of a concordance" ("Integrated methodologies" 290). Literary narratives also help to articulate the cognitive and psychological reflection of agency and selfhood of mankind (Dennett 418).

Fictional narratives tend to restore the voice of the natural world through speech and thus endorse the close knitting of the human-nature relationship. Ursula Le Guin writes, "To include an animal as a protagonist equal with the human is - in modern terms - to write a Fantasy. To include anything on equal footing with the human, as equal in importance, is to abandon realism". Human culture has appropriated the natural environment to fit its particular purposes with little regard for the destruction caused by its self-interest. Through an eco semiotics approach, fantastical literature tries to "construct signs, metaphors, and symbols that not only reflect our own natural environment but also envisage the environment's potential for influencing human perceptions of nature in a mediating fantastic 
realm". Fictional narratives have the ability to encourage the reassessment of the ways in which humans interact with the environment. It helps to produce an understanding and communication with the natural world. As Le Guin states, "Fantasy's green country is one that most enter with ease and pleasure, and it seems to be perfectly familiar to most children even if they've never been out of the city streets" (86). Through fantasy and fiction, the authors can produce a natural landscape sufficient for its own existence and not merely to support the human-centric interests. It provides a narrative in which flora and fauna voice their emotions, in which nature thinks and projects its thoughts, and it exists as a separate entity without any form of human intervention. Conjuring an imaginary landscape provides an alternative way to communicate the real issues of nature to the readers. Using imaginary landscapes to communicate with the natural environment, Maran comes up with three possible outcomes: it helps in appreciating and upholding nature in human thought, a better understanding of the natural environment in the human cultural system and promoting the reader to experience nature first hand.

Thus fantasy and fictional narrative put forth an alternative way for the representation of nature, to discuss the problems in the natural environment and to treat its flora and fauna with the same respect and accord as humans. It provides dialogue, power, and action to the nonverbal entities of nature to evince the salient features of the earth's natural atmosphere. It places nature at the center of the action and thus instigates a paradigm shift. The reader with the help of signs, metaphors, and symbols gets to appreciate nature in a more ecocentric perspective.

With the help of some literary texts, I would now like to emphasize on the importance of decentering anthropocentric interactions and recentering of ecocentric dialogues between man and nature. Jon Favreau's film The Jungle Book (2016) presents man as a part of nature, sharing mutual dependence with animals. The central focus of the movie is about nature and 
its subjects. The film is loaded with connotations and interpretations that generate environmental consciousness. The movie shifts the anthropocentric narratives and inculcates different voices from the jungle to create a balance of the narratives. Mowgli, the man-cub is considered as a part of the wolf pack initially. This rejects the social construct of the human world and the natural world and brings forth an understanding of the ecological balance that arises from the harmonious relationship between the two. More than once, Mowgli is saved by his animal companions. This act of saving a human even at the cost of their own survival shows the benevolence of nature. The movie reverses the character's quality of the animals to introduce them as a living being, similar to humans, with a sense of family, love, and belongings making them emotionally available to the readers to emphasize their loss, their happiness, their habitat, and their struggles. This zoomorphic narration breathes life into animals and gives the viewers more personal experiences into their lives which otherwise seems impossible. Raksha embodies Mowgli's entire relationship with the jungle- she protects, shelters and safeguards him at all times and the bond that they share creates an ecological awareness about the relationships among nature's various subjects. The narrative of the film balances its projection of the emotions and empathy of both nature and the human world. There is no bias or prioritisation of one over the other. This helps to shatter the binary between man and nature and supports an integrated way of coexistence. The movie also tries to capture the ecological inter-connectedness and the mutual respect they share. Every organism acknowledges their share in the ecosystem and respects their boundaries. Mowgli is made to bow and make way as the elephants- the creators of everything around them- pass through. Though Mowgli cannot overcome his human instincts, he uses his intellectual capacity to construct tools to aid other animals. This can be interpreted as a non-destructive way of construction that benefits both nature and mankind. Thus the movie aims to have an 
impact upon the audience's environmental values and behavior and also wants to inspire the viewers to take personal and political action.

The 2009 science fiction film 'Avatar' written and directed by James Cameron is a reflection on the destructive phase of technology. It questions the notion of 'advancements' and presents a visual treat of the interconnectedness and complexity of the Omaticaya people. The work is rooted in fiction, nevertheless, as a movie, Avatar had done much justice in portraying the havoc caused by man's greed, the lifeless machines and the lifeless men controlling them. Contrasting that, it shows nature in its true beauty, complexity, the interrelations, and interdependence between organisms. With all the growth we claim to have, mankind didn't learn to protect the one thing that keeps life possible on this planet. Pandora is the planet where a unique and 'extremely costly' element Unobtanium is found in abundance and humans occupy the planet to extract this. They give the indigenous Omaticaya people road, medicine, education, etc to find a diplomatic solution for allowing humans to dig up the element. This quest to civilize people arise from their own need to reap unobtanium which lies under their 'Tree of Life'. We try to study the complex connections existing in nature using refined instruments but all this knowledge couldn't stop the sky people from destroying the sacred grooves. Neytiri tells Jake that the sky people cannot be taught because they do not see, they do not feel and without feeling the nature one could not learn about it. This shows the narrow mindedness of the people who don't stop to understand or emphasize a greater flow of energy in them. Shahaylu or the sacred bond is through which the Omaticaya people connect with the other organisms. Jake is asked to feel the heartbeat of the horse, tension in its legs, the power in its muscles as he learns to become one of them. Ikaran is a bird used by the Omaticayan's to fly and every Ikaran ride only one rider in his lifetime. The rider and the bird should choose each other. This is a direct contrast to the ways humans tame animals. There is a sense of mutual respect, respect for Ewaya, and respect for the 
energy that flows through every being. When Jake becomes an accepted member of the clan, he also becomes a part of the people and of the energy that they borrowed from the great Ewaya. Grace, a scientist in the mission of understanding the native people, reflects that the wealth of this world is in its people. Jake calls in a favor from the Ewaya, and all the natures force came in to aid them in their fight against the sky people. By showing the sinister face of advancements and by displaying the unparalleled intricacy in which nature sustains, the film pushes forward the need for ecological awareness.

Moana is a 2016 Disney animated feature film about a young girl chosen by the ocean to find the demi-god Maui and restore 'the heart of the ocean'. Moana is a symbolic representation of how we could save nature from its perils of destruction. It sends a strong message on the restoration of nature by finding a way to fix the heart of the matter. The demigod Maui characterizes human greed, domination, and selfishness. With his God-given powers and magical hook, he steals the heart of Te-fiti so that he could possess the power to create life. With this act of stealing he creates an ecological imbalance thus resulting in the deterioration of natural life. Maui represents humanity in its attempt to go beyond its ability and possess things that seem insurmountable. The magical hook represents the human tools used for the exploitation of nature. With the hook, he thought he could conquer nature, but once it was taken from him, Maui is stripped off of his self-worth. His reliance on the hook symbolizes the human need to identify with material possessions. We may have control over the weapons we make but very less over the consequences of its actions. Ti-fiti is mother nature personified so as to portray the changes that affect her as a result of Maui's unpardonable actions. Moana is restricted by her father to not cross the reef because crossing the reef suggests confronting the real issues at stake and amend the mistakes. Only after Moana has delivered Maui across the great ocean and restored the heart of Ti-fiti, the darkness that has slithered into the earth perished. Moana's act of restoring the heart 
symbolizes that only an act of returning and reinstating nature, could save man himself from the wrath. The movie addresses the issue of the dangers of ecological imbalances and shows us the way to restore it by restoring nature. The film intends to educate people on the issues of natural destruction, the changing geographical features and also shows us the ultimate way to revoke the crisis. Moana is implicative of the threat of existence if we are not cautious of our ways.

The Little Prince by Antoine de Saint Exupery, though categorized as a children's book, it is loaded with signs and symbols that render an eco semiotics reading of the characters. The author by using the anthropocentric sign system has subverted the standard meanings that lie within each sign. The book parodies the hysteria of man over material possessions and the objective understanding of 'matters of consequences'. Characters like the man who never smelled a flower, the king who ruled over a planet with no subjects, the man who drinks to forget he's ashamed of drinking, the businessman who is always counting assuming he owns the stars or a geographer who gathers knowledge but never explores ridicule the mundane human senses. The little prince encounters a flower in the desert who tells him, " The wind blows them(people) away. They have no roots and that makes their life very difficult." The flower indicates the importance of having roots - figuratively and metaphorically. Without the tree, the vegetation and the rich diversity of species, life on earth will become implausible. It is nature that helps in sustaining life on the planet. The character of the fox introduces the idea of 'taming', ie, to tame is to establish ties. It is quite contrary to the meaning humans associate with - domestication. Humans should learn to appropriate meanings in an eco semiotics aspect to understand nature adequately. Such appropriations would help to reduce the imbalances in nature- human relationships. After observing the hundreds of plants growing together, the little prince announces, "You are beautiful but you are empty". Manmade resources have their beauty but they mean nothing if it isn't to foster a 
better living environment. The railway switchman reveals that the grown-ups are never satisfied, never pursuing and that they are always half asleep. Only the children know what they are looking for. Little prince remembers the fox's advice, "Men have forgotten this truth- But you must not forget it. You became responsible for your rose.” This is a great message for the whole of mankind. Little prince represents the human race and the rose signifies nature. You are responsible for your environment.

\section{Conclusion}

Altering and accommodating meaning embedded with the anthropocentric sign, sign function, text and code and valuing them as a behaviourally, socially and linguistically complex entity, paves the way for bridging the gap between the human-centered interactions and the ecocentric realm. 


\section{Works Cited}

Bruni, L. E. (2001). Biosemiotics and ecological monitoring. Sign Systems Studies, 29(1), 293-312.

Cameron, James, director. Avatar. 20th Century Fox, 10AD.

Clements, Ron and John Musker, directors. Moana. Disney, 23 AD.

Dennett, Daniel. Consciousness Explained. London: Penguin, 2003. Print.

"Ecocriticism.” Wikipedia, Wikimedia Foundation, 2 Feb. 2020, en.wikipedia.org/wiki/Ecocriticism.

“Ecosemiotics.” Wikipedia, Wikimedia Foundation, 22 Jan. 2020, en.wikipedia.org/wiki/Ecosemiotics\#Literature.

Evernden, N. (1993). The natural alien: Humankind and environment. Toronto, Canada: University of Toronto Press Inc.

Fritz, Justin. "Environmentalism and the 'Ecological Indian' in Avatar: A Visual Analysis." The Arbutus Review, Vol. 3, No. 1, 1969, pp. 67-90., doi:10.18357/tar31201211530. Kongwattana, Pattarapong. "Moana (2016): Negotiating Patriarchy from the Ecofeminist Perspective.” Veridian E-Journel, Vol. 11, No. 4, Jan. 2018, doi:10.3897/bdj.4.e7720.figure2f.

Le Guin, Ursula K. "The Critics, The Monsters, and the Fantasists." Wordsworth Circle 38.1 2 (2007): 83-87. EBSCOhost Academic Search Premier. Web. 09 February 2020. Maran, Timo, and Kalevi Kull. "Ecosemiotics: Main Principles and Current Developments." Geografiska Annaler: Series B, Human Geography, vol. 96, no. 1, 2014, pp. 41-50., doi:10.1111/geob.12035.

Rockström, J., Steffen, W. L., Noone, K., Persson, Å., Chapin III, F. S., Lambin, E., ... \& Foley, J. (2009). Planetary boundaries: Exploring the safe operating space for humanity.Ecology and Society, 14(2), 1-33. 
Saint-Exupery, Antoine De. Little Prince. Oberon Modern Plays, 2020

Young, Jason. "Reframing Our Relationship with Nature: An Ecosemiotic Literature Review." Academia, www.academia.edu/34718146/Reframing_our_Relationship_with_Nature_An_Ecose miotic_Literature_Review. 